\title{
HEALTH AND SAFETY ISSUES IN CHILDREN WITH INTELLECTUAL DISABILITY
}

\section{Munevera Bećarević, Alma Dizdarević, Zulfo Ahmetović, Amila Mujezinović, Esed Omerić}

(C) by Acta Medica Saliniana ISSN 0350-364X

Type of manuscript: Professional papers

\section{Title:}

HEALTH AND SAFETY ISSUES IN CHILDREN WITH INTELLECTUAL DISABILITY

\section{Authors:}

Munevera Bećarević ${ }^{1}$

Alma Dizdarevićz, Zulfo Ahmetović ${ }^{3}$ Amila Mujezinović́ ${ }^{2}$ Esed Omerić ${ }^{1}$

DOI: $10.5457 / 490$

\section{Afiliations:}

Faculty of Medicine, University of Tuzla ${ }^{1}$, Faculty of Education and Rehabilitation, University of Tuzla², Faculty of Education, University of Sarajevo ${ }^{3}$

Received:

11.01.2019.

\section{Corresponding author:}

Munevera Bećarević

Faculty of Medicine, University of Tuzla

Email: munevera.becarevic@ukctuzla

Background: People with intellectual disability, have been shown to become high and frequent users of primary health care services-both general population health professionals and intellectual disability specialists.

Aim: The aim of this paper has been to assess differences of Health and Safety Activities children with intellectual disabilities on the Supports Intensity Scale-Children's Version and to confirm assumptions that support needs are confounded with age, IQ and gender.

Methods: The sample included 377 children with intellectual disabilities in Bosnia and Herzegovina aged 5-16. Most respondents also had the presence of other, concurrent conditions and disorders. Using IQ, the sample was equalized to the level of intellectual functioning, and this data was obtained from the findings and opinions of the Commission for the Categorization of Children with Special Needs.

Results: It was found at the multivariate level there are statistically significant differences between respondents of different ages and IQ in values of type, frequency and time of duration of support. No significant differences between boys and girls were identified at the multivariate level. Healthcare professionals and intellectual disability specialists must work as a team to guarantee any person with intellectual disability possibility to come as close as possible to the standard levels of well-being and health-related quality of life of the general population.

Keywords: intellectual disabilities, health, support needs, well-being

\section{INTRODUCTION}

Intellectual disability $(1,2)$ or disorders of intellectual development (3) is characterized by significant limitations in intellectual functioning and adaptive behaviour, and early age of onset (prior to 18 or during the developmental period). The latest international intellectual disability taxonomy (2) includes four intellectual disability diagnostic categories (mild, moderate, severe, and profound). This definition of an intellectual disability is generally consistent across different diagnostic classification systems, including the Diagnostic and Statistical Manual of Mental Disorders, Fifth Edition (DSM-5) and International Classification of Diseases (ICD), WHO's International Classification of Functioning, Disability and Health (ICF). Epidemiological studies have emerged to elucidate the prevalence of intellectual disabilities. Using a criterion of an IQ below 70 and impaired adaptive behaviour, the overall prevalence of intellectual disability is between $1 \%$ and $3 \%$ globally $(4,5)$. Of those individuals with intellectual disabilities, mild, moderate, severe, and profound intellectual deficits affect about
$85 \%, 10 \%, 4 \%$, and $2 \%$ of the population, respectively (6). The highest rates were seen in low- and middle-income countries and prevalence was higher among studies based on children/adolescents, compared to those based on adults (7).

Many health professionals are unfamiliar with and have received little training in the typical health and functioning issues in persons with intellectual disability (8), meaning they may miss underlying health problems (9) increasing the potential for under-reporting of conditions. People with intellectual disability, have been shown to become high and frequent users of primary health care services-both general population health professionals and intellectual disability specialists. In addition, there are data emerging of different patterns and combinations of morbidities, less focus on preventive interventions, and inattention to population health among people with intellectual disability. Taken together the utilization data particularly suggest a lack of preparedness for people with intellectual disability in general population health delivery (10). 
Social support has been significantly associated to the health-disease process, and the perception of social support by individuals and their relatives has been systematically related to a good health. On the contrary, dysfunctional or discontinuous social support, or its absence, increases the vulnerability of patients to health problems and diseases. Also, the influence of social support has been observed on other positive health indicators, such as well-being (4), perceived health and quality of life (5). Perceived health improves health-related quality of life and adding social support can improve well-being, mainly physical and emotional.

The objective of this research has been to assess differences of Health and Safety Activities children with intellectual disabilities on the Supports Intensity ScaleChildren's Version (11) and to confirm assumptions that support needs are confounded with age, degrees of intellectual disability and gender. With this, the authors intend to increase and improve the evidence on the importance that supports and health assistance have on the quality of life and well-being of children with intellectual disability.

Research is also needed to explore measurementrelated issues and specifically, this article addressed three research questions:
Research Question 1: What intensity of support is needed for children with intellectual disabilities in support Health and Safety Activities on the Supports Intensity Scale-Children's

Research Question 2: How does the trend of intensity of support change with increasing chronological age and degree of intellectual difficulties?

Research Question 3: Are there differences between the support level and gender of the respondents?

\section{METHODS}

The presented results were collected within the project "Psychometric Characteristics of the SIS-C for estimating the intensity of support" financed by the Federal Ministry of Education. The survey included 377 children with intellectual disabilities in Bosnia and Herzegovina aged 5-16. Using IQ, the sample was equalized to the level of intellectual functioning, and this data was obtained from the findings and opinions of the Commission for the Categorization of Children with Special Needs. Detailed characteristics of the sample are shown in Table 1.

Table 1. Demographic characteristics

\begin{tabular}{|l|c|c|}
\hline Variable & $\mathrm{n}$ & $\%$ \\
\hline Gender & & \\
\hline Male & 237 & 62.9 \\
\hline Female & 140 & 37.1 \\
\hline Age group & & \\
\hline $5-6$ & 51 & 13.5 \\
\hline $7-8$ & 56 & 14.9 \\
\hline $9-10$ & 64 & 17.0 \\
\hline $11-12$ & 68 & 18.0 \\
\hline $13-14$ & & 74 \\
\hline $15-16$ & 64 & 19.6 \\
\hline Student'Siq or intelligence level & & 17.0 \\
\hline $55-70$ or Mild & 121 & 32.1 \\
\hline $40-55$ or Moderate & 130 & 34.5 \\
\hline $25-39$ or Severe & 123 & 32.6 \\
\hline$<25$ or Profound & 3 & 0.8 \\
\hline
\end{tabular}

The data were collected stratified into two-year groups: 5-6, 7-8, 9-10, 11-12, 13-14 and 15-16 years old. Furthermore, the sample was stratified in age groups in relation to the level of intellectual functioning (light IQ> 55, moderate IQ 40-55, difficult IQ <40). The SIS-C administration requested that assessments be made of the frequency, duration and type of support that a child needs to be successfully involved in range of Health and Safety Activities. Therefore, when completing the focus was not on the specific skills the child has or the tasks that he was able to perform, but on the types of support that a child needs to fully participate in a range of different activities. The SIS-C consists of a series of items grouped into 7 areas, but for purpose of this study we use section 5. Health and Safety - 8 items:

1. Communicating health-related issues and medical problems, including aches and pains

2. Maintaining physical fitness

3. Maintaining emotional well-being

4. Maintaining health and wellness

5. Implementing routine first aid when experiencing minor injuries such as a bloody nose 
6. Responding in emergency situations

7. Protecting self from physical, verbal, and/or sexual abuse

8. Avoiding health and safety hazards.

An interviewer who interviewed an individual child with intellectual disabilities collected information from at least two respondents. The interviews collected information from the respondents, and on that basis they were evaluated. The interviewer interviewed the interviewees separately or interviewed two or more respondents at the same time (group interview) Respondents were persons who knew the child well, and they were parents or other family members, teachers, or staff involved in directly supporting the child.

Ratings reflected the level of support that a child needs to be successful in each of the observed activities. The concept of being successful is defined as engaging a child in all aspects of a particular activity, in relation to contemporary school and social standards, which resulted in a maximum involvement (i.e. full participation) of the child in the given activity. In other words, successful engagement included the level of achievement / involvement / participation in activities that could be measured with those levels in typical child's peers.

\section{RESULTS}

Through the Health and Safety domain/area and 8 activities, the type of support, frequency and time of duration support on the scale from 0 to 4 are examined. The present study examined support needs on the Health and Safety domain/area children with intellectual disability and the purpose of this study is to confirm assumptions that support needs are confounded with age, IQ and gender.

Table 2. Average values and standard deviation

\begin{tabular}{|l|c|c|c|c|}
\hline \multicolumn{1}{|c|}{ Section } & Values & $\mathrm{N}$ & $\mathrm{M}$ & $\mathrm{SD}$ \\
\hline \multirow{3}{*}{$\begin{array}{l}\text { E - Health and } \\
\text { Safety Activities }\end{array}$} & Type & 377 & 2.75 & 0.991 \\
\cline { 2 - 5 } & Frequency & 377 & 2.78 & 1.014 \\
\cline { 2 - 5 } & $\begin{array}{c}\text { Daily Support } \\
\text { Time }\end{array}$ & 377 & 2.49 & 1.017 \\
\hline
\end{tabular}

Table 2 shows the average values and standard deviation of results of Health and Safety Activities on the Supports Intensity Scale-Children's Version.

Table 3. Average values of individual age groups

\begin{tabular}{|c|c|c|c|c|c|c|c|}
\hline \multirow{2}{*}{} & & \multicolumn{2}{|c|}{} & \multicolumn{2}{c}{ Frequency } & $\begin{array}{c}\text { Daily } \\
\text { Support } \\
\text { Time }\end{array}$ \\
\hline \multirow{2}{*}{ Section } & Age & $\mathrm{N}$ & $\mathrm{M}$ & $\mathrm{SD}$ & $\mathrm{M}$ & $\mathrm{SD}$ & $\mathrm{M}$ \\
\hline \multirow{5}{*}{$\begin{array}{l}\text { E- Health and } \\
\text { Safety Activities }\end{array}$} & $5-6$ & 51 & 3.62 & 0.485 & 3.62 & 0.485 & 3.32 \\
\cline { 2 - 9 } & $7-8$ & 56 & 3.04 & 0.997 & 3.07 & 1.000 & 2.74 \\
\cline { 2 - 9 } & $9-10$ & 64 & 2.87 & 0.742 & 2.89 & 0.746 & 2.53 \\
\cline { 2 - 9 } & $11-12$ & 68 & 2.53 & 0.958 & 2.56 & 0.949 & 2.22 \\
\cline { 2 - 8 } & $13-14$ & 74 & 2.54 & 1.069 & 2.61 & 1.123 & 2.38 \\
\cline { 2 - 8 } & $15-16$ & 64 & 2.14 & 0.877 & 2.16 & 0.987 & 1.98 \\
\hline
\end{tabular}

Table 3 shows the average values of individual age groups on the scale, type and frequency of support needed. As can be seen at the descriptive level, the average values of type, frequency and time of duration of support on section Health and Safety Activities, are reduced in the function of the age. This means that support is of lesser value on older ones compared to younger age groups. These age differences were tested using MANOVA-E procedures. 
Table 4. Significance between children of different age

\begin{tabular}{|l|c|c|c|c|c|c|c|c|}
\hline & \multicolumn{3}{|c|}{ Type } & \multicolumn{3}{c|}{ Frequency } & \multicolumn{3}{c|}{ Daily Support Time } \\
\hline \multicolumn{1}{|c|}{ Effect } & Values & $\mathrm{F}$ & $\mathrm{p}$ & Values & $\mathrm{F}$ & $\mathrm{p}$ & Values & $\mathrm{F}$ \\
\hline Pillai's Trace & 0.435 & 5.019 & $0.000^{* *}$ & 0.403 & 4.622 & $0.000^{* *}$ & 0.390 & 4.456 \\
\hline Wilks' Lambda & 0.613 & 5.426 & $0.000^{* *}$ & 0.639 & 4.929 & $0.000^{* *}$ & 0.652 & 4.705 \\
\hline Hotelling's Trace & 0.557 & 5.780 & $0.000^{* *}$ & 0.499 & 5.186 & $0.000^{* *}$ & 0.472 & 4.901 \\
\hline Roy's Largest Root & 0.377 & 19.891 & $0.000^{* *}$ & 0.323 & 17.040 & $0.000^{* *}$ & 0.279 & 14.696 \\
\hline
\end{tabular}

As shown in Table 4, at the multivariate level there are statistically significant differences between respondents of different ages in values of type, frequency and time of duration of support. On average, the variance value is less that the age is higher. This means that the support time duration has lower values on the older compared to younger age groups. This analysis finds additional evidence in support of the first research question.
An analysis of the differences between children of varying degrees of intellectual disability on Health and Safety Activities was carried out. In addition, the group with the highest degree of intellectual difficulty is shown only descriptively, but did not enter into further analyses due to inequality in the size of the group (only $\mathrm{N}=3$ cases) and because of the lack of variability in that group which does not allow for further multivariate analysis of the variance.

Table 5. Average values of different degrees of intellectual difficulty

\begin{tabular}{|c|c|c|c|c|c|c|c|}
\hline \multirow{2}{*}{} & & \multicolumn{2}{|c|}{} & \multicolumn{2}{c}{ Frequency } & $\begin{array}{c}\text { Daily } \\
\text { Support } \\
\text { Time }\end{array}$ \\
\hline \multirow{2}{*}{ Section } & IQ & N & M & SD & M & SD & M \\
\hline \multirow{3}{*}{$\begin{array}{l}\text { E - Health and } \\
\text { Safety Activities }\end{array}$} & 25 & 3 & 4.00 & 0.000 & 4.00 & 0.000 & 3.50 \\
\cline { 2 - 9 } & $26-39$ & 123 & 3.37 & 0.660 & 3.40 & 0.631 & 3.11 \\
\cline { 2 - 9 } & $40-55$ & 130 & 2.90 & 0.794 & 2.94 & 0.830 & 2.58 \\
\cline { 2 - 9 } & $56-70$ & 121 & 1.92 & 0.893 & 1.93 & 0.943 & 1.74 \\
\hline
\end{tabular}

As can be seen from Table 5, the average values of type, frequency and time of duration of support on Health and Safety Activities are reduced in the function of the height of the IQ value. This means that the type, frequency and time of duration of support are of lesser value on groups with higher IQ than those with lower IQ values. These differences were tested using MANOVA procedures.

Table 6. Significance between children of different degrees of intellectual difficulty

\begin{tabular}{|l|c|c|c|c|c|c|c|c|}
\hline & \multicolumn{3}{|c|}{ Type } & \multicolumn{3}{c|}{ Frequency } & \multicolumn{3}{c|}{ Daily Support Time } \\
\hline \multicolumn{1}{|c|}{ Effect } & Values & $\mathrm{F}$ & $\mathrm{p}$ & Values & $\mathrm{F}$ & $\mathrm{p}$ & Values & $\mathrm{F}$ \\
\hline Pillai's Trace & 0.544 & 19.527 & $0.000^{* *}$ & 0.542 & 19.426 & $0.000^{* *}$ & 0.445 & 14.964 \\
\hline Wilks' Lambda & 0.474 & 23.558 & $0.000^{* *}$ & 0.480 & 23.125 & $0.000^{* *}$ & 0.562 & 17.412 \\
\hline Hotelling's Trace & 1.069 & 27.798 & $0.000^{* *}$ & 1.038 & 27.000 & $0.000^{* *}$ & 0.767 & 19.938 \\
\hline Roy's Largest Root & 1.032 & 53.950 & $0.000^{* *}$ & 0.993 & 51.916 & $0.000^{* *}$ & 0.750 & 39.225 \\
\hline
\end{tabular}

Based on the results of the research shown in Table 6, at the multivariate level there are statistically significant differences between the subjects of different values of IQ in the values of type, frequency and time of duration of support on all scales taken together. On average, the variance value is less when the group has a higher IQ value.

An analysis of the differences in values on Health and Safety Activities was carried out with respect to the gender of the children surveyed. 
Table 7. Average values of support by gender

\begin{tabular}{|c|c|c|c|c|c|c|c|}
\hline & & & \multicolumn{2}{|c|}{ Type } & \multicolumn{2}{c|}{ Frequency } & $\begin{array}{c}\text { Daily } \\
\text { Support } \\
\text { Time }\end{array}$ \\
\hline Section & Sex & N & M & SD & M & SD & M \\
\hline $\begin{array}{l}\text { E - Health and } \\
\text { Safety Activities }\end{array}$ & M & 237 & 2.78 & 0.981 & 2.82 & 1.002 & 2.57 \\
\cline { 2 - 9 } & F & 140 & 2.68 & 1.006 & 2.69 & 1.032 & 2.36 \\
\hline
\end{tabular}

As can be seen from Table 7, at the descriptive level there are gender differences on the scale of type, frequency and time of duration of support. On average, boys have higher values on all scales. However, since these differences can be a reflection of random variations, their significance at the multivariate level is examined.

Table 8. Significance between boys and girls

\begin{tabular}{|l|c|c|c|c|c|c|c|c|}
\hline & \multicolumn{3}{|c|}{ Type } & \multicolumn{3}{c|}{ Frequency } & \multicolumn{3}{c|}{ Daily Support Time } \\
\hline \multicolumn{1}{|c|}{ Effect } & Values & $\mathrm{F}$ & $\mathrm{p}$ & Values & $\mathrm{F}$ & $\mathrm{p}$ & Values & $\mathrm{F}$ \\
\hline Pillai's Trace & 0.014 & 0.750 & 0.630 & 0.009 & 0.504 & 0.832 & 0.016 & 0.855 \\
\hline Wilks' Lambda & 0.986 & 0.750 & 0.630 & 0.991 & 0.504 & 0.832 & 0.984 & 0.855 \\
\hline Hotelling's Trace & 0.014 & 0.750 & 0.630 & 0.010 & 0.504 & 0.832 & 0.016 & 0.855 \\
\hline Roy's Largest Root & 0.014 & 0.750 & 0.630 & 0.010 & 0.504 & 0.832 & 0.016 & 0.855 \\
\hline
\end{tabular}

As can be seen from Table 8, no significant differences between boys and girls were identified at the multivariate level, which relate to the value of the variation of all scales of type, frequency and time of duration of support.

\section{DISCUSSION}

Overall, the findings hypothesized general decrease in the intensity of support needs with age, where is important to note that the standardization sample was further stratified within each age cohort by level of intellectual functioning, suggesting that this pattern of decreasing intensities of support needs occurs across children with intellectual disabilities across a range of intellectual functioning (12). The findings provide important information on assessing support needs in children and youth with intellectual disabilities, namely, that age is an important consideration and developing norms based on age cohorts, as was done for the SIS-C (11) is necessary. The major implication is that planning teams must consider age when planning supports, and there is a need for repeated support needs assessment, particularly during major transitions in a child's life (12).

Most healthcare professionals are aware that it is necessary to implement a comprehensive policy if we want socio-health care to meet the needs and demands of the most vulnerable social groups in order to achieve a higher degree of integration which guarantees equality of opportunities and equity for these population groups (13).
For these reasons there are growing recommendations for the development and use of health indicator surveys to better document inequalities, highlight differences in health and health needs and track improvement over time. In Europe, the Pomona project built upon the generic European Community Health Indicators effort by establishing 18 health indicators for people with intellectual disability: demographics (prevalence of intellectual disability, living arrangements, daily occupation, income/SES, life expectancy); health status (epilepsy, oral health, body mass index, mental health/ psychiatric disorder, sensory capacities, mobility); determinants of health (physical activity, challenging behaviours, psychotropic medications); and health systems (hospitalization and contact with healthcare professionals, health checks, health promotion, specific training for physicians) and identified potential sources for the related data $(14,15,16)$.

\section{CONCLUSION}

In this study we reveal that the average values of type, frequency and time of duration of support on scale Health and Safety Activities, are reduced in the function of the age and reduced in the function of the height of the IQ. Type, frequency and time of duration of support are lesser value on groups with higher IQ than those with lower IQ values and that support is lesser value on older ones compared to younger age groups. At the multivariate level there are statistically significant differences between respondents of different ages in values of type, frequency and time 
of duration of support on all scales taken together. On average, the variance value is less that the age is higher. This means that the support time duration has lower values on the older compared to younger age groups. This analysis finds additional evidence in support of the first research question.

At the multivariate level there are statistically significant differences between the subjects of different values of IQ in the values of type, frequency and time of duration of support on all scales taken together. On average, the variance value is less when the group has a higher IQ value. No significant differences between boys and girls were identified at the multivariate level, which relate to the value of the variation of all scales of type, frequency and time of duration of support.

In this regard, it is necessary to obtain the highest possible individual autonomy through the achievement of the maximum development of their

\section{REFERENCES}

1. AAIDD (American Association on Intellectual Developmental Disabilities). Intellectual disability: definition, classification, and systems of supports. Washington DC, 2010: AAIDD.

2. American Psychiatric Association. Diagnostic and Statistical Manual of Mental Disorders. 5th ed. Arlington, 2013 TX: American Psychiatric Publishing.

3. World Health Organization. Draft of ICD-11 clinical description and diagnostic guidelines: Disorders of intellectual development. Geneva, Switzerland, 2015: Author.

4. Carr A, Linehan C, O'Reilly G, Walsh PN, McEvoy J, editors. The handbook of intellectual disability and clinical psychology practice. London, 2014: Routledge.

5. Harris JC. Intellectual disability: Understanding its development, causes, classification, evaluation, and treatment. New York, 2006: Oxford University Press.

6. King B, Toth K, Hodapp RM, Dykens E. Intellectual disability. Comprehensive textbook of psychiatry; 2009. p. 3444-74.

7. Maulik PK, Mascarenhas MN, Mathers CD, Dua T, Saxena S. Prevalence of intellectual disability: a meta-analysis of population-based studies. Res Dev Disabil. 2011;32(2):419-36.

8. Haveman M, Heller T, Lee L, Maaskant M, Shooshtari S, Strydom A. Major health risks in aging persons with intellectual disabilities: an overview of recent studies. J Pol Pract Intellect Disabil. 2010; 7:59-69.

9. McCarron M, Swinburne J, Burke E, McGlinchey E, Carroll R, McCallion P. Patterns of multimorbidity in an older population of persons with an intellectual disability: results from the intellectual disability supplement to the irish longitudinal study on ageing (IDS-TILDA). Res Dev Disabil. 2013;34:521-7.

10. McCallion P, Swinburne J, Burke E, McGlinchey E, McCarron M. Understanding the similarities and differences in aging physical, cognitive and emotional abilities and/or competences, thus creating adequate and normalized social dynamics which enable individuals with intellectual disability to carry out their basic daily activities and prevent deficiencies or limitations in their activity which may restrict their participation and have an influence on or lead to additional problems and/or dependence. This approach needs to be multidisciplinary. For this reason, healthcare professionals, caregivers, educators, physicians, physical therapists, occupational therapists, speech therapists, psychologists and other professionals must work as a team to correct or minimize those alterations as best as possible, and to guarantee the maximum individual autonomy and social integration so that any person with any kind of disability may have the possibility to come as close as possible to the standard levels of well-being and health-related quality of life of the general population. with an intellectual disability: linking Irish general population and intellectual disability datasets. In: Urbano R, editor. Using secondary datasets to understand persons with developmental disabilities and their families (IRRDD-45). New York, NY: Academic Press; $2013 a$.

11. Thompson JR, Wehmeyer ML, Hughes C, Shogren KA, Seo H, Little TD, Schalock R, Realon RE, Copeland SR, Patton JR, Polloway E, Sheldon D, Tanis S, Tasse MJ. Supports Intensity Scale-Children's Version: Users manual. Washington DC, 2016: American Association on Intellectualand Developmental Disabilities.

12. Shogren KA, Seo H, Wehmeyer ML, Palmer SB, Thompson JR, Hughes C, Little TD. Support Needs of Children with Intellectual and Developmental Disabilities: Age-Related Implications for Assessment. Psychology in the Schools, 2015; 52(9): 874-891.

13. Emerson E, Felce D, Stancliffe RJ. Issues concerning self-report data and populationbased data sets involving people with intellectual disabilities. Intellect Dev Disabil. 2013;51:333-48.

14. Van Schrojenstein Lantman-De Valk HM, Metsemakers JF, Haveman MJ, Crebolder HF. Health problems in people with intellectual disability in general practice: a comparative study. Fam Pract. 2000;17:405-7.

15. Haveman M, Perry J, Salvador-Carulla L, Walsh PN, Kerr M, Van Schrojenstein Lantman-de Valk $H$, Van Hove G, Berger DM, Azema B, Buono S, Cara AC, Germanavicius A, Linehan C, Määttä T, Tossebro J, Weber G. Ageing and health status in adults with intellectual disabilities: results of the European POMONA II study. J Intellect Dev Disabil. 2011;36:49-60.

16. Walsh PN. Health indicators and intellectual disability. Curr Opin Psychiatry. 2008;21(5):474-8 